\title{
Synthesis and Thermal Stability of Bis(8-hydroxy- quinoline)-Schiff Base Coordination Polymers
}

\author{
Emanuel Horowitz and Theodore P. Perros*
}

(June 16, 1964)

\begin{abstract}
This report describes the synthesis of a new bis-bifunctional derivative of 8-hydroxyquinoline, its reaction with a number of divalent, first-row transition metals to form coordination polymers, and a thermogravimetric study of the thermal stability of the polymers. The ligand, 5,5'-[methylenebis ( $p$-phenylenenitrilomethylidyne)]di-8-quinolinol was prepared in a condensation reaction between 5-formyl-8-hydroxyquinoline and 4,4'-methylenedianiline and subsequently treated with the acetate salts of $\mathrm{Mn}(\mathrm{II}), \mathrm{Co}(\mathrm{II}), \mathrm{Ni}(\mathrm{II}), \mathrm{Cu}(\mathrm{II})$, and $\mathrm{Zn}(\mathrm{II})$. The metal coordinated in the backbone of the polymer is shown to be an important factor in governing the thermal stability when the samples are heated in vacuum.
\end{abstract}

\section{Introduction}

In an earlier paper [1] ${ }^{1}$ the authors reported the synthesis and thermal properties of coordination polymers of bis(8-hydroxy-5-quinolyl)methane. The thermal stability of Schiff base and related coordination systems has been studied by other workers [2-7], although not under the conditions used in our experiments. For example, Friihof [2] prepared a variety of interesting 8-hydroxyquinoline-Schiff bases which he reacted with metal ions to obtain insoluble coordination polymers in the form of colored powders. He examined the thermal stability of a number of the polymers by heating $200 \mathrm{mg}$ samples at fixed temperatures and measuring the weight loss after a 12-hr interval.

Marvel and coworkers [3] investigated the thermal stability of $\mathrm{Zn}(\mathrm{II}), \mathrm{Ni}(\mathrm{II})$, and $\mathrm{Cu}(\mathrm{II})$ chelates containing ligands I and II.
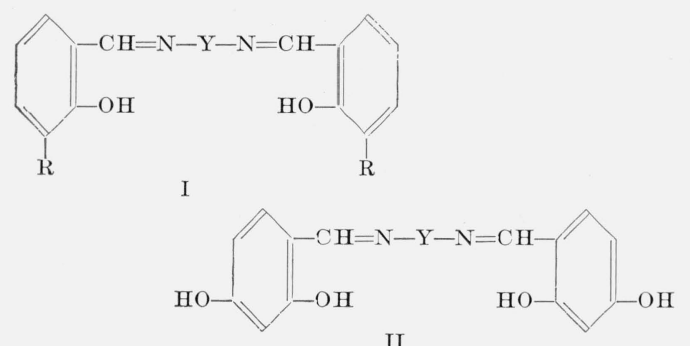

II

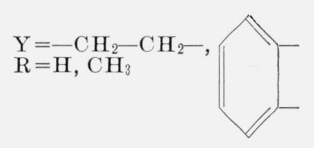

\footnotetext{
${ }^{*}$ Chemistry Department, The George Washington University, Washington, D.C.

i Figures in brackets indicate the literature references at the end of this paper.
}

They found that the copper complexes were always less stable than those of either zinc or nickel, and the relative stability of the two latter complexes depended, to a large extent, upon the nature of the bridging group. Charles [7] studied the heat stabilities of some Schiff base chelates of $N$-alkylsalicylaldimine,

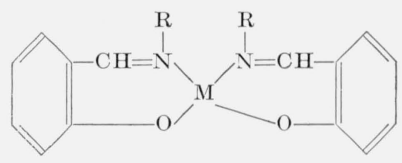

and found that in all cases the copper complexes were less stable than those of zinc. The relative stability of the nickel and the zinc chelates appeared to be a function of the alkyl substituent on nitrogen. The zinc complexes containing heptyl, decyl, and dodecyl groups were more stable than the nickel complexes. However, with propyl and amyl groups on nitrogen, the nickel chelates were more stable than the zinc compounds.

The work to be described here is an extension of the original investigation [1] and deals with the synthesis and thermal stability of coordination polymers of $5,5^{\prime}$-[methylenebis $(p$-phenylenenitrilomethylidyne)] di-8-quinolinol. These polymers differ from those in the first group chiefly because the $-\mathrm{CH}_{2}-$ bridge in bis(8-hydroxy-5-quinolyl)methane has been replaced by a

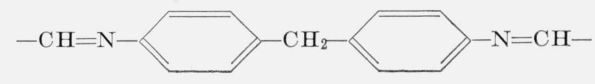

bridging group. The coordination polymers of bis(8-hydroxy-5-quinolyl)methane were found to be very insoluble, even in boiling organic solvents. As is well known, the insoluble nature of coordination polymers has severely limited their use as engineering materials and has impeded more fundamental 
research dealing with such problems as molecular weights and polymer morphology. On the basis of chemical considerations, the bis-bifunctional nature of the ligand leads one to expect that polymers were formed during the reactions with metal ions. This view is supported by infrared and elemental analysis, the insolubility of the products from the reactions and, moreover, by their enhanced thermal stability. The properties of the products differed markedly from the known behavior of the nonpolymeric complexes of 8-hydroxyquinoline. In part, the insertion of the large organic bridge in the present group of polymers was an attempt to improve their solubility characteristics in organic solvents. In addition, it was of interest to study the effect of this large bridging group on the thermal stability and other properties of the coordination polymers.

\section{Experimental Procedure}

Synthesis of $5,5^{\prime}-[$ methylenebis (p-phenylenenitrilomethylidyne)] di-8-quinolinol. The 5-formyl derivative of oxine was prepared by means of a Reimer Tiemann reaction of 8-hydroxyquinoline with chloroform in alkaline solution [8]. The product ultimately obtained from this reaction was extracted with petroleum ether, and on cooling, a brown-orange solid crystallized in the extract. This was recrystallized from acetone, yielding an orange-tan product in the form of fine needles that melted at 178.5-179.5 ${ }^{\circ} \mathrm{C}$.

Anal. Calc. $\mathrm{C}_{10} \mathrm{H}_{7} \mathrm{O}_{2} \mathrm{~N}$ : $\quad$ C $69.4 \quad \mathrm{H} 4.02 \quad \mathrm{~N} 8.09$

Found

C $69.3, \mathrm{H} 4.07, \mathrm{~N} 7.81$, $69.2 \quad 4.01 \quad 8.23$

The 5-formyl oxine $(0.8658 \mathrm{~g})$ and purified $4,4^{\prime}-$ methylenedianiline $\left(0.4957 \mathrm{~g}\right.$, m.p. $\left.92{ }^{\circ} \mathrm{C}\right)$ were refluxed in $35 \mathrm{ml}$ of methanol, using magnetic stirring. After about 15 min a yellow-brown solid formed in accordance with the reaction shown in eq (1).
The reaction mixture was heated for an additional 30 min and then allowed to cool to room temperature, the product was collected, washed with methanol, and dried in vacuum. The yellow powder melted at 229 to $230{ }^{\circ} \mathrm{C}$.
Anal. Calc.
C $78.0 \quad$ H 4.75
$\mathrm{N} 11.0$

Found

C $\begin{array}{lllll}78.1 & \text { H } & 4.96 & \text { N } 11.0\end{array}$

\section{Synthesis of Schiff Base Coordination Polymers}

The coordination polymers were prepared, as shown in the general equation (eq 2 , below), by dissolving the ligand in boiling dimethylformamide ${ }^{2}$ and adding, drop-wise, a stoichiometric amount of the metal acetate contained in a dimethylformamide solution, while the reaction mixture was under reflux conditions. When the cation was added to the solution containing the ligand there was a sudden change in the color of the solution accompanied by the precipitation of the polymer. The polymers, in the form of colored powders, were found to be insoluble in a wide variety of solvents and could not be purified by recrystallization. Therefore, each polymer was collected, wrapped in filter paper prior to insertion in a paper thimble, and extracted with dimethylformamide for $16 \mathrm{hr}$ in a Soxhlet apparatus. This was designed to purify the polymer by extracting unreacted starting materials and soluble nonpolymeric substances. After $16 \mathrm{hr}$ the solution in the extraction flask was highly colored while the solvent in contact with polymer in the extractor was colorless. The polymers were then extracted with absolute alcohol to remove adsorbed dimethylformamide

2 The dimethylformamide was first treated with $\mathrm{KOH}$ pellets and then ${ }^{2}$ The dimethylformamide was first treated with $\mathrm{KOH}$ pellets and then
distilled at atmospheric pressure in the presence of $\mathrm{CaO}$. The fraction which distilled between 152 to $154^{\circ} \mathrm{C}$ was collected and used in this work.

\section{Equation 1:}
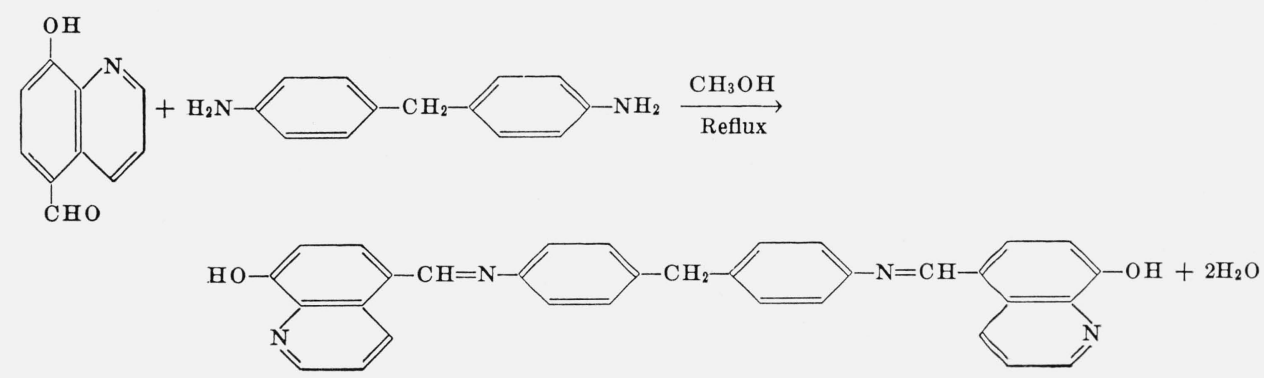

Equation 2:

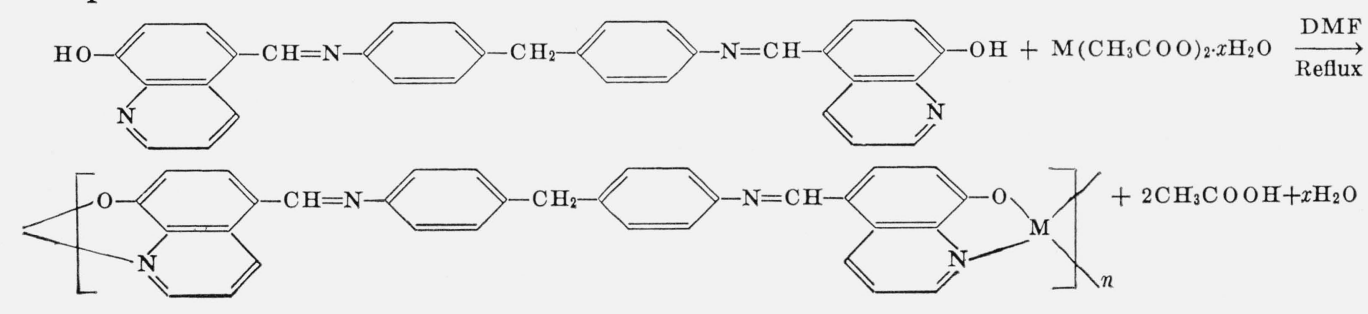


and any alcohol-soluble constituents. The product was dried over $\mathrm{P}_{2} \mathrm{O}_{\tilde{o}}$ in vacuum at $140{ }^{\circ} \mathrm{C}$ for $24 \mathrm{hr}$. The results of the elemental analyses of the polymers are given in table 1 .

TABLE 1. Elemental analyses of coordination polymers

\begin{tabular}{|c|c|c|c|c|c|c|c|c|}
\hline \multirow{2}{*}{ Polymer } & \multicolumn{4}{|c|}{ Calculated, $\%$} & \multicolumn{4}{|c|}{ Found, \% } \\
\hline & $\mathrm{C}$ & $\mathrm{H}$ & $\mathrm{N}$ & M & C & $\mathrm{H}$ & $\mathrm{N}$ & M \\
\hline $\begin{array}{l}{\left[\mathrm{MnL} \cdot \mathrm{H}_{2} \mathrm{O}\right]_{n-}} \\
{\left[\mathrm{MnL} \cdot 2 \mathrm{H}_{2} \mathrm{O}\right]_{n}}\end{array}$ & $\begin{array}{l}68.4 \\
66.3\end{array}$ & $\begin{array}{l}\text { 4. } 17 \\
\text { 4. } 39\end{array}$ & $\begin{array}{l}9.67 \\
9.37\end{array}$ & $\begin{array}{l}9.48 \\
9.19\end{array}$ & 68.2 & 4. 10 & & \\
\hline $\begin{array}{l}{\left[\mathrm{CoL} \cdot \mathrm{H}_{2} \mathrm{O}\right]_{n}} \\
{\left[\mathrm{CoLL} \cdot 2 \mathrm{H}_{2} \mathrm{O}\right]_{n}}\end{array}$ & $\begin{array}{l}67.9 \\
65.9\end{array}$ & $\begin{array}{l}\text { 4. } 14 \\
\text { 4. } 36\end{array}$ & $\begin{array}{l}9.60 \\
9.31\end{array}$ & $\begin{array}{c}10.1 \\
9.80\end{array}$ & 67.3 & 4. 58 & 9. 00 & 9.20 \\
\hline $\begin{array}{l}{\left[\mathrm{NiL} \cdot \mathrm{H}_{2} \mathrm{O}\right]_{n-}} \\
{\left[\mathrm{NiL} \cdot 2 \mathrm{H}_{2} \mathrm{O}\right]_{n}}\end{array}$ & $\begin{array}{l}68.0 \\
65.9\end{array}$ & $\begin{array}{l}\text { 4. } 15 \\
\text { 4. } 36\end{array}$ & $\begin{array}{l}9.61 \\
9.32\end{array}$ & $\begin{array}{c}10.1 \\
9.76\end{array}$ & 66.2 & 4. 34 & 9. 54 & 10.4 \\
\hline $\begin{array}{l}{\left[\mathrm{CuL} \cdot \mathrm{H}_{2} \mathrm{O}\right]_{n}} \\
{\left[\mathrm{CuL} \cdot 2 \mathrm{H}_{2} \mathrm{O}\right]_{n--}}\end{array}$ & $\begin{array}{l}67.4 \\
65.4\end{array}$ & $\begin{array}{l}\text { 4. } 11 \\
\text { 4. } 32\end{array}$ & $\begin{array}{l}9.53 \\
9.24\end{array}$ & $\begin{array}{l}10.8 \\
10.5\end{array}$ & 69.3 & 4.11 & 9. 46 & 11. 2 \\
\hline $\begin{array}{l}{\left[\mathrm{ZnL} \cdot \mathrm{H}_{2} \mathrm{O}\right]_{n--}} \\
{\left[\mathrm{ZnL} \mathrm{L} \cdot 2 \mathrm{H}_{2} \mathrm{O}\right]_{n-}}\end{array}$ & $\begin{array}{l}67.2 \\
65.2\end{array}$ & $\begin{array}{l}\text { 4. } 10 \\
\text { 4. } 31\end{array}$ & $\begin{array}{l}9.50 \\
9.22\end{array}$ & $\begin{array}{l}11.1 \\
10.8\end{array}$ & 66.9 & 4. 19 & 9.12 & 10.7 \\
\hline
\end{tabular}

$\mathrm{L}=\mathrm{C}_{33} \mathrm{H}_{22} \mathrm{O}_{2} \mathrm{~N}_{4}$

\section{Thermogravimetric Analysis}

The thermal stability of the $\mathrm{Mn}(\mathrm{II}), \mathrm{Co}(\mathrm{II}), \mathrm{Ni}$ (II), and Zn(II) $5,5^{\prime}$-[methylenebis ( $p$-phenylenenitrilomethylidyne)]di-8-quinolinol coordination polymers was studied under vacuum conditions using an Eyraud Electronic Thermobalance. ${ }^{3}$ A $50-\mathrm{mg}$ sample contained in a platinum crucible was heated from room temperature to $1000{ }^{\circ} \mathrm{C}$ at a heating rate of $2.5^{\circ} \mathrm{C} / \mathrm{min}$. The weight loss was determined as previously described [1]. The thermal stability of the $\mathrm{Cu}(\mathrm{II})$ coordination polymer was evaluated with a modified Cahn Electronic Balance to be described in a subsequent publication, after it was demonstrated on reference materials that the data were in agreement with results obtained with the Eyraud Balance. For each polymer, at least two samples were taken, and thermogravimetric analysis curves were obtained on each sample.

\section{Results and Discussion}

The weight loss of each polymer, on a percentage basis, over the temperature intervals studied are listed in table 2. These data are plotted in figure 1 where each curve represents the average of two separate runs conducted on different days.

The initial slopes in the thermograms probably represent the volatilization of water, organic solvent such as dimethylformamide, and low molecular weight moieties. For example, the Mn(II) coordination polymer lost approximately 6 percent of its weight prior to the sharp break in the thermogram while the weight loss for the $\mathrm{Co}(\mathrm{II})$ and Ni(II) coordination polymers was about 5 to 8 percent.

\footnotetext{
3 Eyraud Recording Balance Manual, Anthony- M. Kohler, 535 West 110th Street ,New York, N.Y.
}

TABLE 2. Percentage weight loss of polymers between 25 to $1000{ }^{\circ} \mathrm{C}$ (Heating Rate in Vacuum; $2.5^{\circ} \mathrm{C} / \mathrm{min}$ )

\begin{tabular}{|c|c|c|c|c|c|}
\hline \multirow{2}{*}{$\begin{array}{c}\text { Tempera- } \\
\text { ture }\end{array}$} & \multicolumn{5}{|c|}{ Percentage weight loss (avg of two runs) } \\
\hline & $\mathrm{Zn}$ & $\mathrm{Cu}$ & $\mathrm{Ni}$ & Co & Mn \\
\hline $\begin{array}{r}{ }^{\circ} \mathrm{C} \\
25 \\
50 \\
75 \\
100 \\
125\end{array}$ & $\begin{array}{l}0.2 \\
1.2 \\
3.0 \\
4.3 \\
4.7\end{array}$ & $\begin{array}{l}0 \\
0.2 \\
1.1 \\
2.2 \\
2.8\end{array}$ & $\begin{array}{l}0 \\
0.1 \\
.5 \\
.6 \\
.9\end{array}$ & $\begin{array}{r}0 \\
0.1 \\
.4 \\
.8 \\
1.4\end{array}$ & $\begin{array}{l}0 \\
0 \\
0 \\
0 \\
0\end{array}$ \\
\hline $\begin{array}{l}150 \\
175 \\
200 \\
225 \\
250\end{array}$ & $\begin{array}{l}5.1 \\
5.5 \\
6.2 \\
7.5 \\
8.6\end{array}$ & $\begin{array}{l}3.1 \\
3.1 \\
3.2 \\
3.8 \\
4.5\end{array}$ & $\begin{array}{l}1.3 \\
2.1 \\
2.2 \\
2.6 \\
2.9\end{array}$ & $\begin{array}{l}1.9 \\
2.6 \\
2.9 \\
3.2 \\
4.0\end{array}$ & $\begin{array}{l}0 \\
0 \\
0.4 \\
.6 \\
1.2\end{array}$ \\
\hline $\begin{array}{l}275 \\
300 \\
325 \\
350 \\
375\end{array}$ & $\begin{array}{r}9.8 \\
10.6 \\
12.1 \\
13.1 \\
14.3\end{array}$ & $\begin{array}{r}5.4 \\
6.3 \\
7.4 \\
9.8 \\
16.5\end{array}$ & $\begin{array}{l}3.5 \\
3.9 \\
4.7 \\
6.3 \\
9.0\end{array}$ & $\begin{array}{l}4.4 \\
4.5 \\
4.8 \\
6.2 \\
7.0\end{array}$ & $\begin{array}{l}1.3 \\
1.6 \\
2.1 \\
2.4 \\
2.8\end{array}$ \\
\hline $\begin{array}{l}400 \\
425 \\
450 \\
475 \\
500\end{array}$ & $\begin{array}{l}\text { 15. } 1 \\
\text { 16. } \\
\text { 19. } 0 \\
26.0 \\
33.5\end{array}$ & $\begin{array}{l}33.5 \\
45.7 \\
47.6 \\
48.5 \\
49.3\end{array}$ & $\begin{array}{l}13.4 \\
19.6 \\
23.0 \\
26.0 \\
28.1\end{array}$ & $\begin{array}{r}7.9 \\
11.0 \\
14.6 \\
20.0 \\
25.0\end{array}$ & $\begin{array}{r}3.2 \\
4.0 \\
4.7 \\
6.4 \\
17.8\end{array}$ \\
\hline $\begin{array}{l}525 \\
550 \\
575 \\
600 \\
650\end{array}$ & $\begin{array}{l}35.5 \\
37.7 \\
39.9 \\
42.3 \\
48.1\end{array}$ & $\begin{array}{l}50.0 \\
50.7 \\
51.3 \\
51.9 \\
52.7\end{array}$ & $\begin{array}{l}30.2 \\
32.8 \\
34.7 \\
37.1 \\
42.7\end{array}$ & $\begin{array}{l}26.9 \\
29.5 \\
32.4 \\
35.4 \\
41.9\end{array}$ & $\begin{array}{l}24.7 \\
28.8 \\
30.3 \\
31.7 \\
35.2\end{array}$ \\
\hline $\begin{array}{l}700 \\
750 \\
800 \\
850 \\
900\end{array}$ & $\begin{array}{l}53.0 \\
57.9 \\
60.4 \\
62.4 \\
64.3\end{array}$ & $\begin{array}{l}54.1 \\
54.9 \\
55.4\end{array}$ & $\begin{array}{l}48.0 \\
50.4 \\
54.9 \\
55.5 \\
59.3\end{array}$ & $\begin{array}{l}49.8 \\
57.7 \\
63.9 \\
67.2 \\
70.5\end{array}$ & $\begin{array}{l}39.3 \\
43.3 \\
49.0 \\
54.8 \\
56.5\end{array}$ \\
\hline $\begin{array}{r}950 \\
1000\end{array}$ & $\begin{array}{l}65.9 \\
68.3\end{array}$ & & $\begin{array}{l}60.0 \\
64.5\end{array}$ & $\begin{array}{l}73.9 \\
76.6\end{array}$ & $\begin{array}{l}63.8 \\
68.3\end{array}$ \\
\hline
\end{tabular}

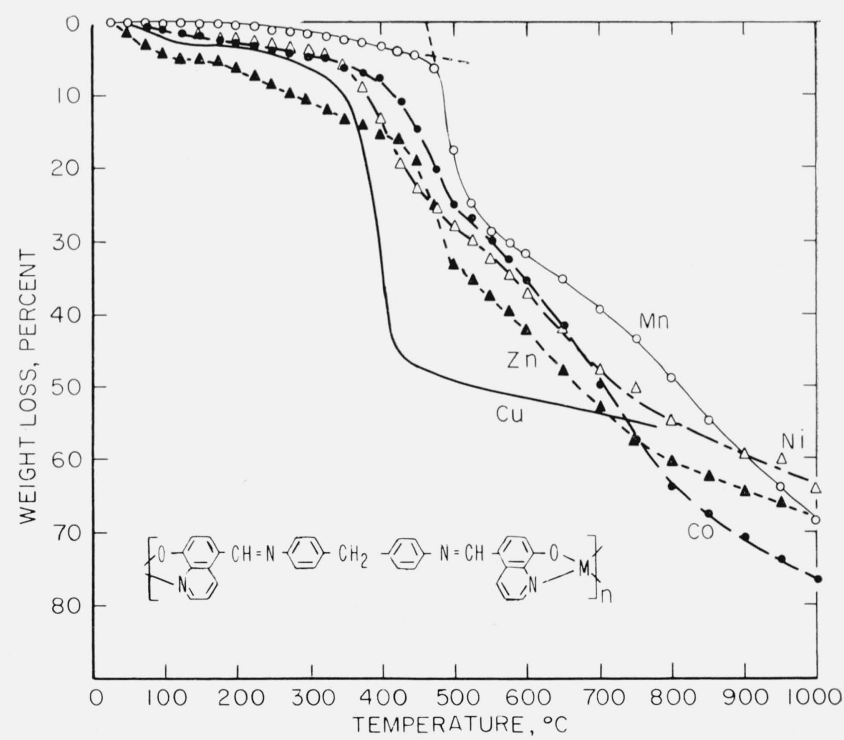

Figure 1. Thermograms of $\mathrm{Mn}(\mathrm{II}), \mathrm{Co}(\mathrm{II}), \mathrm{Ni}(\mathrm{II}), \mathrm{Cu}(\mathrm{II})$, and $\mathrm{Zn}(\mathrm{II}) 5,5^{\prime}-[$ methylene bis (p-phenylenenitrilomethylidyne) di-8-quinolinol coordination polymers.

(Heating rate in vacuum, $2.5^{\circ} \mathrm{C} / \mathrm{min}$.)

These values agree closely with the calculated 6 percent water content in these polymers based on $\left[\mathrm{MnL} \cdot 2 \mathrm{H}_{2} \mathrm{O}\right]_{n}$, where $\mathrm{L}$ represents the ligand. The weight loss of the $\mathrm{Zn}(\mathrm{II})$ polymer up to $425{ }^{\circ} \mathrm{C}$ amounted to about 17 percent, and these volatiles 
may have contained solvent and low molecular weight compounds in addition to water.

After this initial weight loss a rather sharp break occurred in each of the thermograms, signifying the onset of a decomposition process accompanied by a rapid loss of volatile fragments. As a measure of thermal stability, the decomposition temperature of the polymers was determined by the procedure utilized earlier [1]. Briefly, as shown in figure 1 by the dashed lines on the thermogram for the Mn polymer, this involved the drawing of straight linesthrough the experimental points on the expanded thermogram, before and after the initial sharp break in the curve that occurred at moderately low weight losses. The intersection of these two lines was then projected to the temperature axis and this temperature was arbitrarily defined as the decomposition temperature. These temperatures, for each run, are listed in table 3 and are plotted in figure 2 as a function of the atomic number of metal incorporated in the backbone of the polymers.

\section{TABLE 3. Decomposition temperatures} of coordination polymers

\begin{tabular}{c|c|c|c}
\hline & \multicolumn{3}{|c}{ Decomposition temperature, ${ }^{\circ} \mathrm{C}$} \\
\cline { 2 - 3 } $\begin{array}{c}\text { Coordination } \\
\text { polymer }\end{array}$ & Run 1 & Run 2 & A vg. \\
\cline { 2 - 3 } & & & \\
\hline $\mathrm{Mn}$ & 475 & 465 & 470 \\
$\mathrm{Co}$ & 410 & 420 & 415 \\
$\mathrm{Ni}$ & 375 & 385 & 380 \\
$\mathrm{Cu}$ & 345 & 355 & 350 \\
$\mathrm{Zn}$ & 430 & 430 & 430 \\
& & & \\
\hline
\end{tabular}

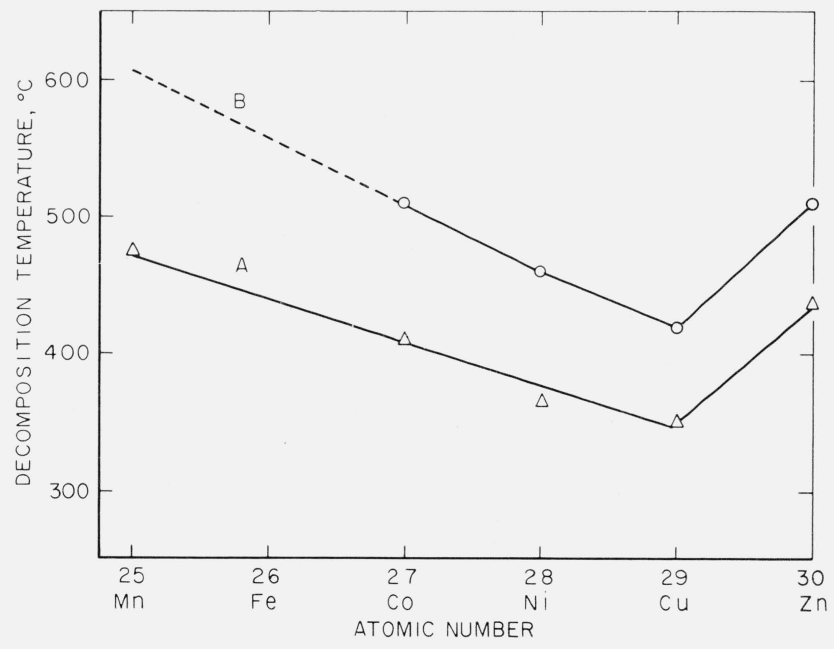

FIgURE 2. Plot of decomposition temperatures of polymers versus atomic number of coordinated metal.

A. 5,5'-[methylenebis ( $p$-phenylenenitrilomethylidyne)] di-8-quinolinol polymers. B. Bis(8-hydroxy-5-quinolyl)methane polymers.

It is interesting to note the marked similarity between the shapes of the plots for the polymers of $5,5^{\prime}$-[methylen ebis ( $p$-phenylenenitrilomethylidyne)] di-8-quinolinol (curve A) and bis(8-hydroxy-5-quinolyl)methane (curve B), reported earlier [1]. In curve $\mathrm{A}$, a linear relationship is seen to exist between the decomposition temperature and the atomic number of the metal, for the polymers containing $\mathrm{Mn}(\mathrm{II}), \mathrm{Co}(\mathrm{II}), \mathrm{Ni}(\mathrm{II})$, or $\mathrm{Cu}(\mathrm{II})$, with the temperature decreasing from about $470^{\circ} \mathrm{C}$ to approximately $350{ }^{\circ} \mathrm{C}$. A rather sharp break occurs in the thermogram for the Mn-Schiff base polymer at about $470{ }^{\circ} \mathrm{C}$, the critical temperature at which accelerated weight loss ensues. No such break was observed in the thermogram of the Mn-bis(8-hydroxy-5-quinolyl)methane polymer, probably because the loss of water and other volatile constituents below the decomposition temperature obscured this point. However, the present work, as well as the thermal characteristics of the metal chelates of 8-hydroxyquinoline [1], tenids to substantiate the extrapolation shown in curve B. The Zn(II) 5,5'-[methylenebis ( $p$-phenylenenitrilomethylidyne)] di-8-quinolinol polymer shows a departure from the thermal stability trend established by the other first-row, divalent transition metals. In fact, its decomposition temperature is about $90{ }^{\circ} \mathrm{C}$ higher than that of the analogous $\mathrm{Cu}(\mathrm{II})$ polymer. The procedures developed by Doyle [9], and Horowitz and Metzger [10] for calculating activation energies and reaction order were found to be inapplicable to the coordination polymers of 8-hydroxyquinoline derivatives in the instances in which the data were tested. Obviously, the decomposition temperature alone is a crude measure of the thermal stability of the samples and more refined and sensitive criteria for evaluating the polymers are currently under examination.

A number of conclusions may be deduced from an examination of the curves shown in figure 2. First, the substitution of a large organic bridge for the $\mathrm{CH}_{2}$ group in the $5,5^{\prime}$-position of the ligand lowers the apparent decomposition temperature of the polymers by 80 to $100{ }^{\circ} \mathrm{C}$. Secondly, the decomposition mechanism, near the temperature at which accelerated weight loss occurs, appears to involve metalligand scissions in both polymer systems and is dependent on the nature of the metal which unites the ligands in the polymer. At this time there is little detailed information about the nature of decomposition over the entire temperature range used in this investigation but the mechanism does not appear to be a simple one.

It would be quite informative if values for the bond angles and bond distances were available for these polymers, particularly at the metal-ligand site, so that one could correlate these data with the thermal stability of the polymers. Unfortunately, only one definitive structural study of an 8-hydroxyquinolate system has been made. This was the work of Merritt and coworkers [11] on Zn-8-hydroxyquinolate. This paper reported the bond distances for $\mathrm{Zn}-\mathrm{O}$ and $\mathrm{Zn}-\mathrm{N}$ as 2.05 and $2.06 \AA$, respectively, and indicated that the 5-membered ring formed on chelation was under strain. Thus, the $\mathrm{Zn}-\mathrm{N}-\mathrm{C}_{8}$ angle was found to be $111.8^{\circ}$ rather than the anticipated $120^{\circ}$ (fig. 3 ). For the divalent metal oxides, when the M-O interatomic distances are plotted versus the atomic numbers of the metals, the relationship depicted in figure 4 is obtained. Thus it is apparent that the 


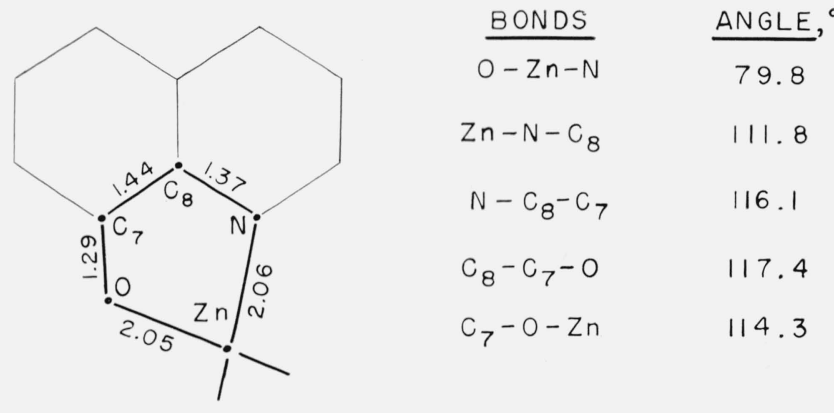

FIg URE 3. Bond distances $(\AA)$ and bond angles in 5-membered chelate ring.

(Data from Merritt, Cady, and Mundy)

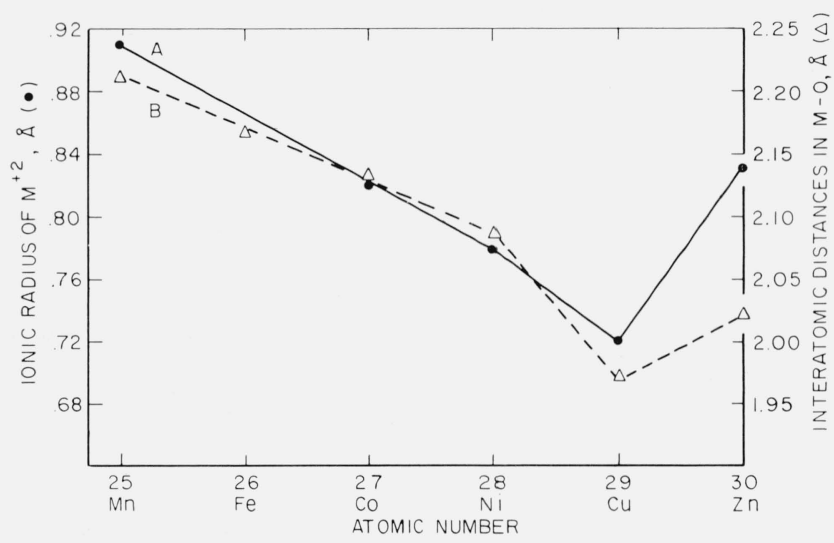

Figure 4. Plot of ionic radius(-) and interatomic distances in metal oxides $(\Delta)$ virsus atomic number of metal.

$\Delta$ Wyckoff, R. W. G., Crystal Structure, Interscience Publishers, Inc., 1951; International Tables for X-ray Crystallography, The Kynoch Press, Birmingham, England (1962), table 4.1

Ahrens, L. H., Geochim Cosm. Acta 2,155 (1952).

bond distances are related to the periodic properties of the metal. Also shown in figure 4 is the relationship between the ionic radii of the metals and their atomic number. The shape of these plots bears a striking resemblance to those shown in figure 2 (curves A and B) where the decomposition temperature has been related to the atomic numbers of the metals in the polymers.

Returning to table 2 it can be seen that by the time the temperature reached $1000{ }^{\circ} \mathrm{C}$ the Co polymer had lost about 75 percent of its original weight while the weight loss of the remaining polymers amounted to 65 to 68 percent. During the run, the furnace was maintained at $1000{ }^{\circ} \mathrm{C}$ for about $8 \mathrm{hr}$ until the sample lost no additional weight. In table 4 the values obtained for the final residues and volatiles are compared with the calculated metal and $\mathrm{C}, \mathrm{H}, \mathrm{N}, \mathrm{O}$ content of the original polymers. For the $\mathrm{Cu}, \mathrm{Ni}$, and Co samples, the residues differed from the calculated metal content in the original polymers by about 10 percent, on a relative basis. Some of the residues contained metal oxides, which may have been formed when the apparatus was opened to the air after the pyrolysis. This could, in part, account for the high results obtained for the residues from the $\mathrm{Mn}, \mathrm{Co}$, and $\mathrm{Ni}$ coordination polymers. There is some evidence to indicate that the metal oxides may not be formed during the decomposition of some of the polymers.

\begin{tabular}{|c|c|c|c|c|}
\hline \multirow{2}{*}{ Polymer } & \multicolumn{2}{|c|}{ Founda } & \multicolumn{2}{|c|}{ Calculated } \\
\hline & Residue & Volatiles & Metalb & $C, H, N, O$ \\
\hline $\begin{array}{l}\mathrm{Mn} \\
\mathrm{Co} \\
\mathrm{Ni} \\
\mathrm{Cu} \\
\mathrm{Zn}\end{array}$ & $\begin{array}{c}\% \\
12.8 \\
11.3 \\
12.1 \\
9.3 \\
\text { trace }\end{array}$ & $\begin{array}{c}\% \\
87.2 \\
88.7 \\
87.9 \\
90.7 \\
100\end{array}$ & $\begin{array}{r}\% \\
9.2 \\
9.8 \\
9.8 \\
10.5 \\
10.8\end{array}$ & $\begin{array}{c}\% \\
90.8 \\
90.2 \\
90.2 \\
89.5 \\
89.2\end{array}$ \\
\hline
\end{tabular}

a After pyrolysis at $1,000^{\circ} \mathrm{C}$ until the residue reached constant weight.

bBased on $\left[\mathrm{ML} \cdot 2 \mathrm{H}_{2} \mathrm{O}\right]$ where $\mathrm{L}=\mathrm{C}_{33} \mathrm{H}_{22} \mathrm{O}_{2} \mathrm{~N}_{4}$.

For the Zn-Schiff base polymer, only a trace of residue remained, indicating that essentially the entire sample volatilized under the conditions of the experiment. This finding is also in keeping with the proposed decomposition mechanism involving the rupture of metal-ligand bonds in that any metallic zinc or even zinc oxide formed during polymer degradation would have volatilized at $1000{ }^{\circ} \mathrm{C}$ in vacuum. Additional experiments are under way at the present time in which the decomposition products are being analyzed in the mass spectrometer. These experiments should provide more definitive information about the mechanism of decomposition for the coordination polymers of bis(8-hydroxyquinoline) derivatives.

\section{References}

[1] Horowitz, E., and Perros, T. P., J. Inorg. Nucl. Chem. 26, 139 (1964).

[2] Friihof, E. J., Ph. D. Thesis, University of Illinois (1961).

[3] Marvel, C. S., Aspey, A. S., and Dudley, E. A., J. Am. Chem. Soc. 78,4905 (1956).

[4] Marvel, C. S., and Tarköy, N., J. Am. Chem. Soc. 79, $6000(1957)$.

[5] Martin, K. V., J. Am. Chem. Soc. 80, 233 (1958).

[6] Bailar, J. C., Jr., and Goodwin, H. A., WADC Tech. Report 58-51, Part III, April 1960, pp. 66-73.

[7] Charles, R. G., J. Inorg. Nucl. Chem. 9, 145 (1959).

[8] Clemo, G. R. and Howe, R., J. Chem. Soc. 3552 (1955).

[9] Doyle, C. D., J. Applied Poly. Sci. 5, No. 15, 285 (1961).

[10] Horowitz, H. H. and Metzger, G., Anal. Chem. 35, 1464 (1963).

[11] Merritt, L. L., Jr., Cady, R. T., and Mundy, B. W., Acta Cryst. \%, 473 (1954). 